\title{
DO QUE NÃO SE PODE ESCAPAR: \\ REFLEXÕES (TEÓRICO-)(LITERÁRIAS) PARA UM PENSAMENTO DA RESPONSABILIDADE DA ARTE
}

\author{
- GABRIEL SALVI PHILIPSON
}

\section{RESUMO}

Neste texto, procurei pensar a relação entre arte e responsabilidade ao desenvolver o problema da responsabilidade do acontecimento tal como estruturado por Bakhtin em seu primeiro escrito, "Arte e esponsabilidade". Meu objetivo foi testar os limites dessa relação proposta por Bakhtin, remetendo para isso a textos que pudessem servir a tal propósito, tal como a obra posterior de Bakhtin, a prosa de Bolaño e a de Bulgákov, bem como um artigo de Safatle. Ao fazer isso, sugeri que Bakhtin reivindica uma posição complexa e radical em relação a esse problema, o que me levou — entre outras coisas — a ressignificar sua obra posterior e a atitude de El Ojo Silva no conto que leva seu nome, bem como a apontar inconsistências na crítica ao cômico operada por Safatle e, por fim, ainda, a perceber a ambiguidade trágica da crítica ao poder soviético perpetrada por Bulgákov.

Palavras- chave: Literatura e ética, arte e responsabilidade, Bakhtin e cinismo

\section{ABSTRACT}

In this text I tried to think the relation between art and answerability by advancing the problem of the answerability of the event in the same way as formulated by Bakhtin in his first text, "Art and Answerability". My aim was to test the limits of this Bakhtinian relation by addressing it to texts that could fit such purpose, such as the latter writings of Bakhtin, Bolaño's and Bulgakov's prose, as well as a paper of Vladimir Safatle. By doing this I suggest that Bakhtin claims an intricate and radical position concerning this problem. This led me to think - among other things - about the following: a) different possible meanings of the latter writings of Bakhtin; $b$ ) the behavior of El Ojo Silva in the short story that carries his name; c) inconsistencies in Safatle's criticism of Bakhtinian's theory about the comical; d) and finally a tragic ambiguous aspect of Bulgakov's criticism of soviet power.

Keywords: Literature and etics, art and answerability, Bakhtin and cinism 
São Paulo, julho de $2016^{1}$

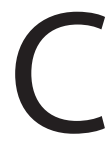

omo pensar uma responsabilidade do acontecimento? Se no mais das vezes o homem se deixa levar pela mecanicidade externa de suas atividades, em uma aceitação irrefletida da normalidade do cotidiano, não há a mais profunda responsabilidade no atrevimento da arte de se distanciar do caráter corriqueiro da vida? Essa é a questão que está no fundo da afirmação de Bakhtin em seu primeiro texto conhecido, escrito em 1919, "Arte e responsabilidade": "quando o homem está na arte não está na vida, e vice-versa" (BAKHTIN, 2015, p. XXXIII). Mas como pensar a relação entre esses dois âmbitos de modo consequente? Para Bakhtin, só há um nexo entre o tempo da criação e o tempo da "prosa do dia a dia" por meio da responsabilidade: eu devo responder com minha vida a fim de que seu "todo" não permaneça inativo. No entanto, essa responsabilidade à kantiana tem para Bakhtin seu correlato em uma culpa que é dupla: a arte tem culpa pela trivialidade da vida e o "homem da vida" pela "esterilidade" — pela não contaminação - da arte. A culpa da arte aparece não apenas porque ela não é capaz de contaminar completamente a vida de acontecimento, mas também por dar à vida o horizonte do acontecimento. Sem esse, a normalidade não poderia nem ao menos almejar a uma ruptura. Ao rompê-la, tem culpa o artista que não leva em conta o significado disso, usando, por exemplo, a desculpa da inspiração artística para justificar o descolamento de responsabilidade da arte em relação à vida. Ao mesmo tempo, aqueles que trabalham em vistas da mecanicidade são culpados por fecharem a vida ao acontecimento da arte.

O jovem Bakhtin aponta que só uma responsabilidade radical pode responder a esse rasgo instaurado pela arte: agir na vida contando com a arte, criar respondendo pela vida. Essa resposta aparentemente razoável e concebível para sua época camufla o lugar incomum de Bakhtin, lugar da possibilidade de perceber o típico problema modernista da relação entre arte e vida em termos de responsabilidade do acontecimento.

Assim, por exemplo, o crítico e teórico inglês T. J. Clark lê esse breve texto percebendo esse lugar incomum de Bakhtin, mas tomando-o como pura expressão do horizonte de expectativas dos primeiros anos da década de 1920 soviética. Ao se perguntar sobre em que lugar El Lissitzki estaria no debate sobre "arte e responsabilidade" do período com seu "Propaganda em quadro na rua", sugere que em uma posição radicalmente crua e contraditória em relação à responsabilidade, o que seria em parte uma repetição dos argumentos de $\mathrm{Ba}$ khtin:"Puts art on the streets. Not to be afraid to adopt the hectoring, acusatory tone of Trotsky's speech", mas, ao mesmo tempo, não ter "illusions about the enormity of the task", pois
[1] A marca temporal faz-se necessária, na medida em que este texto, embora só agora publicado, fora o principal catalizador do processo final de escrita da minha dissertação defendida em março/2017. Parte dele - sem a referência a Bolaño e revisada a partir de comentários de leitura de Marcos Natali e dos colegas Fábio Roberto Lucas e Jorge Manzi - foi incorporada naquele todo maior. É também dessas reflexões que se seguiram outros trabalhos meus apresentados em outras ocasiões, o que de alguma forma repete 0 roteiro daqueles que, antes de mim, se repetiram, repetição de repetições que - supunha - deveria prover algum consolo diante desta outra repetição de repetições. 
[2] A referência é ao Arte e revolução, em que Trotski fundamenta talvez o lado mais cru da responsabilidade da arte para com o acontecimento. any art that believed it could pose the question in less than apocalyptic terms was fooling itself utterly and dooming itself to the worst kind of failure - the failure of pretended praticality in a situation where practice (and value, and representation, and production, and all the vulgar prose of life) was precisely the category in doubt. (CLARK, 1999, p. 263)

Para Clark, esse lugar de El Lissitizki colocaria um fim ao estado de coisas modernista, ou seja, à dicotomia entre arte e vida. No entanto, para isso é preciso que a noção de vida seja quebrada em duas. Por um lado, vida vira rua na aproximação que Clark faz de Bakhtin com El Lissitzki e Trotski². Por outro, vira a pretensa praticidade almejada pela arte propagandística. A complexidade do argumento de Clark aponta para a questão de como pensar a arte tomando a vida quando esta já está previamente tomada pelo tempo do acontecimento. Talvez com uma arte propagandística que finja praticidade. Ou seja, talvez levando à arte o aspecto da praticidade da vida, tornando a arte prática. Mas o aspecto prático da vida que adentra a arte nesse caso faz desta uma propaganda. É claro, no entanto, que nem a Revolução pode ser tomada completamente como um acontecimento na vida, nem a arte de El Lissitzki havia sido completamente dominada pela vida prática, ou seja, havia se tornado propaganda. Assim, mesmo com a divisão da noção de vida em duas outras noções, ocorre tanto a manutenção da impossibilidade de redução da arte à vida e vice-versa em diversos níveis da contraposição entre elas, como também dos próprios termos da contraposição (arte e vida) que não são completamente renovados ou ressignificados, o que está de acordo com o que Bakhtin veicula em seu texto.

Não é por meio da aniquilação dos âmbitos de arte e vida que Bakhtin pode estar além do estado de coisas modernista, mas sim pela noção de responsabilidade. Contudo, aqui a noção de responsabilidade foi compreendida de modo cru, como uma responsabilidade nem tanto revolucionária, mas já partidária, no sentido de uma apropriação a posteriori do acontecimento revolucionário por um determinado grupo político e artístico, quando se compreende o âmbito da vida a partir do lugar da propaganda. Aqui está a outra parte do argumento de Bakhtin que El Lissitzki não recupera: a propaganda artístico-política não instaura uma relação responsável entre o acontecimento da arte e a vida, mas procura apropriar-se (ou tomar posse) do acontecimento que tomou a vida por meio da normalização da arte. Ao fazer isso, reinstaura uma relação de poder que não pode ser de modo algum denominada de responsável. E, com isso, tanto a noção de arte como a de responsabilidade como tal presentes no texto de Bakhtin perdem o incomum de seu lugar, tornam-se sincrônicas ao seu tempo e ocultam sua conexão com a obra posterior e mais conhecida de Bakhtin.

Talvez o que esteja em jogo aqui seja a multivocidade dos termos. O próprio 
Bakhtin em outro texto ainda da década de 1920, “O problema do conteúdo, do material, e da forma na estética literária" (1924), apesar de ainda adotar certa retórica positivista, sistematiza uma crítica teórica filosófica à teoria formalista da literatura, na qual repõe a questão de outro modo, se aproveitando dessa multivocidade dos termos da dicotomia.

Nesse texto, sua acusação principal aos "novos" teóricos da literatura ${ }^{3}$ de seu país refere-se ao fato de que eles não seriam capazes de pensar filosoficamente o problema que se colocaram. Ao analisarem somente a forma e o material, bem como ao tentarem compreender a literatura desde o ponto de vista da ciência natural ou da linguística, eles deixam de lado o problema da relação da forma e do material com o conteúdo, o mundo, a realidade e os valores éticos.

É claro que uma abordagem da literatura que só lide com o conteúdo não pode ser chamada de científica para Bakhtin, mas a abordagem formal que abre mão de pensar a unidade entre forma e conteúdo, entre arte e vida, está abdicando de problematizar filosoficamente a fundo a questão que eles mesmos se colocaram e, com isso, é falha.

\section{[...] o desejo de construir uma ciência a todo custo e o mais rápido possível sempre acarreta uma grande queda do nível da proble- mática, um empobrecimento do objetivo submetido a estudo, $e$ até a substituição desse objeto (no nosso caso, da obra de arte literária) por outra coisa bem diferente. [...] Construir uma ciên- cia sobre este ou aquele domínio da criação cultural, mantendo toda a complexidade, plenitude e originalidade do objeto, é um trabalho extremamente difícil (BAKHTIN, 2010, p. 10).}

A reivindicação de Bakhtin em relação aos formalistas então não é tanto a de não perceberem o fundamento de sua escola na estética romântica alemã - tal como sugere Todorov ${ }^{4}$-, ou talvez sim, mas apenas na medida em que isso signifique que o problema está em erigir uma teoria de modo (contraditoriamente) filosoficamente ingênuo, uma teoria que não seja capaz de levar às últimas consequências seus pressupostos.

A posição científica desses trabalhos não é satisfatória porque, afinal de contas, ela é condicionada por uma atitude incorreta ou, na melhor das hipóteses, metodicamente imprecisa, da poética por eles elaborada para com a estética sistemático-filosófica geral. [...]

Não se pode superar a discordância metodológica no campo do estudo da arte por meio da criação de um novo método — um a mais a tomar parte no conflito geral dos métodos, que exploraria
[3] Minha intenção aqui não é a de tratar da disputa mesmo entre Bakhtin e os formalistas, mas sim a de reconstruir os argumentos de Bakhtin em vista do problema da responsabilidade colocado por ele em seu primeiro texto. Não se trata, portanto, de tomada de posição por Bakhtin, mas de um estudo crítico de seus argumentos. Por isso, acabamos deixando de lado a possível resposta formalista a Bakhtin. Além disso, para alguma noção do contexto em que essa disputa se deu e o lugar de Bakhtin nas inúmeras críticas que foram feitas aos formalistas no período, (ver CLARK, 2014, pp. 186196): "The widespread reaction against Formalism broke down into a right and a left wing. The right wing was made up of all those who based their objections on one or another of the traditional schools of criticism, such as those biographical or historical approaches that had been taught in the university before the Revolution. The most powerful arguments from the right were mounted less by literary critics than by philosophers, such as Gustav Spet or Alexander Smirnov, or by those who were thoroughly at home in philosophy. Bakhtin had a certain affinity with this camp, if only because he fully subscribed to its charge that the Formalists' ingenious interpretations of particular works lacked a theoretical base in a full-blown aesthetics. This was the characteristic charge of the Formalists' right-wing opponents. The attack from the left, chiefly mounted by such eminent Marxists as Trotsky and such representatives of sociological criticism as P. N. Sakulin, maintained that the Formalists ignored social and political factors in their work. Although Bakhtin shared many 
of these left-wing reservations as well about the Formalists, the philosophical poverty behind their methodological practice is chiefly what occupies him in 'The Problem of Content'” (CLARK, 2014, pp. 188-189). Em relação a essa longa citação, o que talvez estou tentando explorar é em que medida para Bakhtin criticar a pobreza filosófica dos formalistas é igualmente criticar a falta de elementos sociais e políticos - éticos - em seus trabalhos, ou seja, em que medida há uma inseparabilidade dessa crítica que é o que faz de sua posição e de sua crítica aos formalistas extremamente atual.

[4] Ver: TODOROV, 2015, p. XVII: “Portanto, Bakhtin não critica a própria oposição entre arte e não arte, entre poesia e discurso cotidiano, mas o ponto onde os formalistas procuram situá-la. [...] A crítica de Bakhtin incide, portanto, sobre os formalistas, mas não sobre o âmbito da estética romântica de que são oriundos. O que ele thes censura não é seu 'formalismo', e sim seu 'materialismo'; poderíamos até dizer que Bakhtin é mais formalista do que eles, se tornarmos a dar à 'forma' seu sentido pleno de interação e de unidade dos diferentes elementos da obra (sentido que também não está totalmente ausente entre os formalistas); é esse outro sentido que Bakhtin tenta reencontrar, introduzindo estes sinônimos valorizados: 'arquitetônica' ou 'construção'”. Como é possível perceber, para Todorov Bakhtin está meramente contrapondo uma posição filosófica por outra - é claro que, no limite, Bakhtin chegará a uma posição filosófica; mas mais do que tudo sua posição ainda mais radical é a de somente a seu modo o caráter fatual da arte - mas sim, por meio da argumentação sistemático-filosófica do fato e da singularidade da arte na unidade da cultura. (BAKHTIN, 2010, p. 14).

Com uma retórica cientificista que posteriormente irá abandonar, porque contradiz com sua própria reivindicação, o ainda jovem Bakhtin não está interessado em fundamentar filosoficamente o formalismo ou em alargá-lo, mas sim em pensar mesmo algo radical que já estava indicado naquele seu primeiro texto: a unidade, o nexo entre arte e vida, entre forma material e conteúdo ético. Esse nexo agora aparece como perfazendo uma unidade na cultura. Trata-se de pensar filosoficamente, então, o papel que apenas a arte é capaz de exercer no campo da cultura, e não simplesmente de criar uma nova vertente para se somar às muitas já existentes.

Com sua reivindicação se põe em um lugar complexo e crítico: sua discordância em relação ao formalismo não se trata, portanto, de uma crítica superficial ao seu materialismo, mas sim de uma condenação do próprio desejo de criação de uma nova escola ou "método" por si mesmo, uma criação que, filosoficamente ingênua, não é capaz de ir além da superfície dos problemas filosóficos já contidos nas escolas já em disputa.

Mesmo assim, ainda seria possível parecer que Bakhtin propõe uma extensão do formalismo que segundo ele só seria capaz de realizar bem a segunda tarefa; entretanto, seria preciso uma verdadeira reviravolta na "estética material" para que ela atendesse às reivindicações bakhtinianas preocupadas com o nexo entre arte e vida, agora entendido também como nexo entre forma e conteúdo (valor, ética). Por isso que, para ele, é importante postular, entre outras coisas, a diferença entre as formas arquitetônicas e composicionais - entre forma do conteúdo e forma do material - , bem como exigir que se devesse, mesmo que não fosse seu objeto principal de análise, ao menos ter em vista a experiência estética fora arte. Com isso, o problema do formalismo é ainda mais profundo, e atinge a interioridade de seu método: ele, além do mais, também não é capaz de compreender como o próprio material atua no interior da obra:

\begin{abstract}
A estética material não pode estabelecer a diferença essencial entre o objeto estético e a obra exterior, entre a articulação e as ligações no interior deste objeto e as articulações e ligações materiais no interior da obra; por toda parte ela mostra uma tendência de misturar estes elementos. (BAKHTIN, 2010, p. 21).
\end{abstract}

Os formalistas então não dão conta nem da arte que adentra a vida, nem — o que é mais problemático para uma teoria estética — da vida ou conteúdo que adentra a $a^{2} e^{5}$. 
Sem a pretensão de esgotar a análise dos textos de Bakhtin citados ${ }^{6}$, nem todos os problemas neles contidos, é possível com o que foi dito sustentar a hipótese de que para Bakhtin o modo de se pensar a responsabilidade do acontecimento a partir da dicotomia arte e vida - interpretada de diversos modos em sua multivocidade - não passava pela possibilidade de se desvencilhar da arte ou da instituição da arte, mas tomava a tarefa de assumir o caráter radical das possibilidades de sua institucionalidade.

Talvez a radicalidade de Bakhtin esteja em assumir um lugar fronteiriço $\mathrm{e}$ crítico-reflexivo em meio ao fogo cruzado da exaltação de ânimos no fervor do acontecimento revolucionário. Com isso, se não pode ou não quis abandonar (ou superar) os termos da dicotomia arte-vida, em nome de uma complexificação do problema estético posto em sua época, podemos ver em seus trabalhos mais conhecidos - como o estudo da cultura carnavalesca e da poética de Dostoiévski - um desenvolvimento do problema posto por seu primeiro texto, a saber, o que pensa a responsabilidade da quebra da normalidade instituída pelo acontecimento da arte. Como pensar uma radicalidade deste tipo?

Podemos vislumbrar um problema parecido ao de Bakhtin ao longo da prosa de Bolaño. Trata-se da questão de como superar a dicotomia entre arte e vida. Pode parecer que, para Bolaño, é a própria arte como instituição que cria uma barreira para com a vida, e que, portanto, se trata de abandonar a arte em nome de alguma efetividade na vida. Quando estou na arte não estou na vida, $\mathrm{e}$ não ajo para resolver os problemas que entrevejo em minha atividade artística; quando ajo, não sou capaz de perceber o abismo para o qual, cantando, me dirijo - o destino de todo latino-americano. Aqui a contraposição arte e vida aparece como a contraposição da passividade e compreensão da arte com a atividade e a cegueira da vida. Don Pedro, poeta espanhol e personagem de Amuleto (1999), parece incorporar em si o lado da passividade e a compreensão da arte em relação à vida. Em sua "mirada tan triste" para o vaso sem flores, entrevê a compreensão da vida (talvez a de que o que exista seja somente incompreensão) — ou seja, "el infierno o una de sus puertas secretas" — nas reflexões de Auxilio Lacouture, personagem narradora em primeira pessoa do romance:

Y a veces me ponía a reflexionar, cuando él ya no estaba en la habitación o cuando no me miraba, yo me ponía a reflexionar e incluso me ponía a mirar el florero en cuestión o los libros antes señalados y llegaba a la conclusión (conclusión que por otra parte no tardaba en desechar) de que allí, en esos objetos aparentemente tan inofensivos, se ocultaba el infierno o una de sus puertas secretas (BOLAÑO, 1999, p. 7).

Mas sua "mirada tan triste" é passiva, o que incomoda a tal ponto Auxilio que reivindicar que qualquer posicionamento filosófico tomado - seja 'formalista', seja 'materialista', ou qualquer outro - implica em problemas filosóficos que devem ser enfrentados, e não normatizados e deixados de lado.

[5] Não deixa de ser provocador constatar a semelhança dessa reivindicação por uma análise mais complexa da obra de arte que leve em conta três de seus momentos - forma, conteúdo, material com a reivindicação de Heidegger de uma relação também tripla da obra de arte em A origem da obra de arte. Neste texto, Heidegger diz que, para pensar a essência da obra de arte, caímos em um círculo hermenêutico de três instâncias que igualmente constituem uma superfície aprofundável: o aspecto coisal (material) da obra de arte; o artista que faz da coisa uma obra de arte e não um artesanato ou outra coisa (forma); a arte que faz do artista alguém que produz uma obra de arte e não outra coisa (conteúdo) (HEIDEGGER, 2003, p. 1). "A obra surge da e pela atividade do artista para o senso comum. Mas por meio de que e de onde o artista o é artista? Pela obra, pois que seja pela obra que se conhece o mestre significa que a obra é que faz do artista um mestre da arte. 0 artista é a origem da obra. A obra é a origem do artista. Um não é sem o outro. Ao mesmo tempo, nenhum dos dois se sustenta sem o outro. Artista e obra são em si mesmos e na sua relação recíproca por meio de um terceiro que é o primeiro, por meio daquilo de onde artista e obra de arte recebem seu nome, por meio da arte". Infelizmente, não será possível desenvolver essa semelhança aqui e explorar as ressonâncias e as questões que surgem dessa relação. 
[6] Mesmo sendo inumeráveis os estudos sobre e a partir de Bakhtin, exponho aqui alguns poucos textos mais ou menos introdutórios (uma antologia que não se pretende completa, apenas sugestiva) que poderiam contribuir para o aprofundamento das questões aqui perseguidas: para a contextualização, o já citado Clark (2014) e também Holquist (2010); para estudos sobre responsabilidade, Holquist et al. (1990) e Nielsen (2002); para uma reivindicação do filosófico, em comparação com Heidegger (SAMPAIO et al. 2015), e em relação ao pensamento não-oficial da década de 1930 soviética desde uma perspectiva do nietzschianismo russo, Groys (2009). E também uma obra de 1924 de autoria controversa, "Discurso na vida e discurso na arte" (VOLOSHINOV, 1976), na qual o problema da unidade entre vida e arte é recolocado e leva a uma reflexão sobre a relação entre o discurso e o mundo.

[7] Vale chamar a atenção para uma relação interessante que pode haver com Heidegger aqui quando este está pensando em Ser e tempo também a abertura para o filosófico e a saída da vida fática a partir do exemplo do instrumento que quebra e deixa de funcionar, deixando de se conformar com o mundo do utilizável (ou com a mecanicidade da vida) e abrindo-se para uma surpresa, nos abrindo para o problema da existência - ou, seria melhor dizer, da morte: "A estrutura do ser de utilizável como instrumento é determinada pelas remissões. [...] Na perturbação da remissão - no não poder ser empregado para... a remissão torna-se, no entanto, expressa [...]. Com esse despertar do ver-ao-redor da remissão para o respectivo para-isto, este fica
[...] me puse a mirar el florero que él miraba con tanta tristeza, y pensé: tal vez lo mira así porque no tiene flores, casi nunca tiene flores, y me acerqué al florero y lo observé desde distintos ángulos, y entonces (estaba cada vez más cerca, aunque mi forma de aproximarme, mi forma de desplazarme hacia el objeto observado era como si trazara una espiral) pensé: voy a meter la mano por la boca negra del florero (BOLAÑO, 1999, p. 8).

Auxilio, na última hora, reflete mais uma vez e não toma qualquer atitude contra o vaso - talvez porque tenha percebido que este pudesse ser apenas o símbolo da vida propriamente dita e que teria oportunidade para conhecer e agir no inferno que o florero representa de outras maneiras mais efetivas.

Já Mauricio Silva - "Ilamado el Ojo" Silva, personagem do conto que leva seu nome, Ojo Silva (2000) - segue outro caminho, a saber, o de evitar "meter la mano por la boca negra del florero", ou seja, "escapar de la violencia": ao longo de sua vida "siempre intentó escapar de la violencia aun a riesgo de ser considerado cobarde, pero de la violencia, de la verdadera violencia, no se puede escapar" (BOLAÑO, 2014, p. 215).

Do que não se pode escapar ou a verdadeira violência, o nexo entre vida e arte, e a responsabilidade. Também Ojo Silva não escapa - mesmo que tenha encontrado o que não se pode escapar do outro lado do planeta -, ao decidir abandonar seu ofício de fotografia (arte) e fugir (atitude ativa na vida) com os garotos que estavam para serem castrados em um bordel na Índia. Até ali havia vivido como que evitando enfrentar o problema arte-vida: migrou para a Europa onde se fez fotógrafo de amenidades. Em um dos trabalhos, vai para a Índia fotografar para "el típico reportaje urbano, una mezcla de Marguerite Duras y Hermann Hesse, el Ojo y yo sonreímos, hay gente así, dijo, gente que quiere ver la India a medio camino entre India Song y Sidharta, y uno está para complacer a los editores" (BOLAÑO, 2014, p. 220). Mas no meio da mecanicidade ${ }^{7}$ da vida, vai encontrar a necessidade de se enfrentar o problema. Assim que, antes de fugir, tira uma foto de um dos garotos, enfrentando-o de um modo não adequado a tal ponto que o próprio El Ojo "sabía que estaba condenando[se] para toda la eternidade, pero lo hice" (BOLAÑO, 2014, p. 224). Talvez porque esse ato não seria responsável para com a vida — para com o nexo entre arte e vida —, assumindo um ato violento em nome da instituição arte. Mas em seguida sua atitude muda: El Ojo Silva decide fugir com os garotos, decide se tornar a mãe deles, aparentemente abandonando a arte como instituição e como algo passivo — como uma fotografia que não atua sobre o mundo.

Mas será que esse ato - ao mesmo tempo irresponsável e responsavelmente subversivo, que rompe com a ordem das coisas — é de fato um abandono da 
arte enquanto polo passivo da dicotomia em nome de uma vida enquanto seu polo ativo? Pensando através do fortalecimento dos polos arte-vida proposto pelo primeiro texto conhecido de Bakhtin, talvez não se trate de uma atitude que abandona a arte pela vida, mas de uma que ressignifica a ambos.

Não podemos ver em seu "itinerário" 8 pós-fuga, descrito de modo idílico, uma performance? Trata-se de ver na sua transformação em mãe uma "artealização da vida" - expressão que Favaretto toma de empréstimo de Hélio Oiticica em seu artigo "Deslocamentos: entre a arte e a vida" (2011). Ou seja, perceber nesse encontro com a violência e com a responsabilidade que, no fim das contas, não passou de uma suspensão na ordem mecânica de sua existência, um deslocamento da passividade da arte até a possibilidade de uma

\section{[...] arte participante, agenciando nas ações uma outra ordem do simbólico - o comportamento, visando a instaurar a 'vontade de um novo mito'; uma imagem da arte como atividade em que não se distinguam os modos de efetivar programas estéticos e exigências ético-políticas (FAVARETTO, 2011, p. 99).}

Nesse sentido, é pertinente a pergunta de Galard que Favaretto situa ao final do artigo: "Pode-se conceber uma arte da existência que não leve a nenhuma obra?" (FAVARETTO, 2011, p. 108) `.

Se for possível pensar o "itinerário" de El Ojo Silva como performance, então sua tomada de decisão não rompe com a dicotomia arte-vida e o lugar de Bakhtin nessa dicotomia ainda permanece significativo. Com efeito, no fim da transformação em mãe ${ }^{10}$ de El Ojo, podemos ver que talvez a instituição arte tenha sobrevivido:

Después llegó la enfermedad a la aldea y los niños murieron. Yo también quería morirme, dijo el Ojo, pero no tuve esa suerte. Tras convalecer en una cabaña que la lluvia iba destrozando cada día, el Ojo abandonó la aldea y volvió a la ciudad en donde había conocido a sus hijos. Con atenuada sorpresa descubrió que no estaba tan distante como pensaba, la huida había sido en espiral y el regreso fue relativamente breve. Una tarde, la tarde en que llegó a la ciudad, fue a visitar el burdel en donde castraban a los niños. Sus habitaciones se habían convertido en viviendas en donde se hacinaban familias enteras. Por los pasillos que recordaba solitarios y fúnebres ahora pululaban niños que apenas sabían andar y viejos que ya no podían moverse y se arrastraban. Le pareció una imagen del paraíso (BOLAÑO, 2014, p. 228). visível e com ele a conexão-da-obra, a 'oficina' inteira como aquilo onde a ocupação sempre já estava. A conexão-instrumental não reluz como algo nunca visto, mas como um todo já constante e de antemão avistado no ver-ao-redor. Mas, com esse todo, o mundo se anuncia" (HEIDEGGER, 2012, pp. 226-7) (Ver toda "A análise da mundidade do mundo-ambiente e da mundidade em geral").

[8] "El resto, más que una historia o un argumento, es un itinerário" (BOLAÑO, 2014, p. 226).

[9] E Favaretto prossegue: Segundo ele [Galard], "o obstáculo radical para a edificação de si mesmo como obra de arte" reside numa "imprevisibilidade absoluta: a existência do outro", que introduz a desordem na "escultura de si". É assim que "a atividade artística pratica uma experimentação da qual a reflexão ética tem todo o interesse em se nutrir"; abrindo, como dizia Oiticica, a possibilidade da "descoberta do mundo, do homem ético, social, político, enfim da vida como perpétua atividade criadora" (FAVARETTO, 2011, p. 108).

[10] Agradeço à Sofia Nestrovski por sugerir mais uma relação possível entre Oiticica e El Ojo Silva: a maternidade a partir dos ninhos e bólides do artista brasileiro. 
Vale pensar como ao fim e ao cabo a passividade do itinerario - que estamos tentando ver aqui como seu ato performativo — se mantém, mesmo que ressignificada: em certo sentido, a experiência que El Ojo Silva viveu entre a fuga e a morte dos meninos teve muito pouca influência na mudança social que depois ele vai descobrir ter havido. De certo modo, podemos ver até mesmo como sua atitude significou certo grau de alienação do mundo da vida, já que fica totalmente desinformado durante esse período das mudanças que estão ocorrendo em assuntos como esse diretamente implicados em sua atividade.

Isso leva a constatarmos uma possível conservação das instâncias da arte e da vida: a vida alterou-se de fato à revelia de sua atividade "artealizadora da vida", mas, ao mesmo tempo, houve também uma "vitalização" da arte, talvez no sentido de uma "constituição de modos de existência ou, como dizia Nietzsche, para a invenção de novas possibilidades de vida" (FAVARETTO, 2011, p. 99). Talvez possamos ver nisso uma resposta responsável ao acontecimento.

Mas talvez podemos pensar a radicalidade da posição de Bakhtin também de outro modo, deslocando a pergunta, já que ronda a figura de Bakhtin certa ideia de que por teorizar a comicidade e o riso, seria estranho a ele a reivindicação de responsabilidade do acontecimento. A questão aqui é pelos limites do acontecimento cômico: seria ele capaz de instaurar de fato um nexo entre arte e vida?

Para Safatle, no texto "Sobre o riso que não reconcilia: Notas a respeito da 'Ideologia da ironização'” (2008), não: tal acontecimento não é capaz de romper "a forma ingênua, o mais das vezes mecânica" (BAKHTIN, 2015, p. XXXIII) com que o artista e o homem estão unificados. Concebendo a multivocidade das noções de arte e vida a partir da dicotomia Lei/anomia (caráter subversivo/normatividade sócio-político-jurídica), Safatle defende que a teoria da cultura carnavalesca de Bakhtin perpetua o establishment, porque pensada a partir de festas populares da Idade Média que não seriam capazes de romper com o status quo ao suspenderem o domínio da Lei:

Se a relação fosse realmente de oposição, seria difíil explicar como o ordenamento jurídico é capaz de se reconfigurar imediatamente após o período de anomia, sem que tal período implique em necessidade de reorientação dos processos de normatização. Ou seja, eles retornam tal como eram antes. Assim, para além da tentativa bakhtiniana de entificação de um certo caráter subversivo do riso popular que teria no carnaval seu espaço social privilegiado, riso popular que seria uma das raízes do cinismo grego, devemos insistir na complementaridade entre posição da norma e sua ironização paródica (SAFATLE, 2008, p. 8). 
É digno de nota que há ao menos uma possibilidade de defender o caráter subversivo da teoria bakhtiniana concordando com a ideia de Safatle de que a ironização paródica do carnaval seria complementar à "posição da norma": trata-se de distinguir entre carnaval e teoria da carnavalização. Com isso, seria possível entender a esta como uma tentativa de pensar a cultura oficial stalinista não como seu contraponto, mas como a sua definição que a desmascara. É isso que sugere Groys a seguir:

[...] Se se encontra no "monologismo" de Bakhtin, igualmente e com razão, uma metáfora para a cultura stalinista oficial, o carnaval não é, contudo, nenhuma "alternativa democrática" àquela, conquanto seu lado irracional e destrutivo. A descrição de Bakhtin do carnaval lembra acima de tudo a atmosfera dos processos espetaculosos stalinistas com seus incriveis "coroamentos e destronamentos"(GROYS, 2009, p. 223, apud PHILIPSON, 2015, p. 126).

Aqui, trata-se de pensar o carnaval enquanto período de anomia complementar à Lei em um momento em que essa dicotomia foi invertida: a própria lei contém em si a suspensão carnavalesca de si mesma. Nesse caso, seria possível considerar que a teoria de Bakhtin está pensando o nexo entre arte e vida a partir da categoria de responsabilidade, acusando "a atmosfera dos processos espetaculosos stalinistas", ela, sim, de irresponsável, porque carnavalesca.

Mas outra possibilidade de defender o caráter subversivo da posição bakhtiniana - subversivo enquanto modo de entender a responsabilidade como nexo entre arte e vida (como foi possível a T. J. Clark ver uma resposta ao debate da relação entre arte e responsabilidade no fato de El Lissitzki levar a arte à rua) - é pensar que, em alguns casos, é responsável reivindicar certa irresponsabilidade, que nesses casos há um dever de irresponsabilidade. Já vimos como é possível ver algo de irresponsável na atitude de El Ojo Silva, mas é Derrida quem reflete sobre a responsabilidade que envolve a literatura que tem como pressuposto a licença dada "ao escritor para dizer tudo o que queira ou tudo o que possa, permanecendo, ao mesmo tempo, protegido de toda censura, seja religiosa ou política" (DERRIDA, 2014, p. 52):

A liberdade de dizer tudo é uma arma política muito poderosa, mas pode imediatamente se deixar neutralizar como ficção. Esse poder revolucionário pode tornar-se muito conservador. $O$ escritor pode, igualmente de fato ser considerado irresponsável. Ele pode, eu diria até que deve, às vezes, reivindicar certa irresponsabilidade, pelo menos no tocante a poderes ideológicos,
[11] Safatle tem razão em ver Bakhtin no centro da discussão sobre o cinismo, mas ao não tomar o devido cuidado teórico e contextual, acaba mais apontando as dificuldades de possíveis interpretações de Bakhtin que não dão conta de pensar a responsabilidade, do que as dificuldades do próprio pensamento bakhtiniano. Preocupado que está em apontar o potencial conservador de certo cinismo contemporâneo, pensa este como coadunando com o poder ao se voltar contra o discurso crítico, não tendo olhos para enxergar a complexidade de um pensamento que se volta ao mesmo tempo contra as falhas de ambos, na busca por uma resposta mais radicalmente responsável. 
[12] Sobre a dificuldade de Safatle lidar criticamente com a complexidade que envolve o poder soviético, remeto à discussão pública que teve com Ruy Fausto em 2013 - a qual faço alusão não para tomar partido nela (como se simplesmente concordássemos com Ruy Fausto), mas para reforçar a relação controversa de Safatle com tal poder -, como na passagem a seguir (CASTRO, 2013): "Quanto ao leninismo, a atitude de Safatle é em geral de simpatia, embora ele trate pouco do assunto de forma suficientemente direta. No final de A paixão do negativo, ele incorpora, à última hora, se não me engano, um desenvolvimento sobre Lenin. Nas páginas iniciais de $A$ esquerda que não teme dizer o seu nome, agradece a seu pai por ter-lhe dado o nome de Vladimir.... Detalhe sem importância? Piscada de olho para o leitor? Não sei. De qualquer modo, não basta. Isso é muito pouco, para quem quer escrever um livro conclamando a esquerda a assumir seus princípios básicos".

[13] Epígrafe do artigo de Safatle: "Celui qui plaisante à la tête du governement tend à la tyrannie. Saint-Just" (SAFATLE, 2008, p. 1)

[14] Aqui, dou alguns elementos para constituir o percurso do pensamento de Bakhtin desde seus primeiros escritos. Em minha dissertação, trato de modo mais geral do contexto exterior das décadas de 1920 e 1930. de tipo zhdanoviano, por exemplo, que tentam cobrar dele responsabilidades extremamente determinadas perante os órgãos sociopolíticos e ideológicos. Esse dever de irresponsabilidade, de se recusar a responder por seu pensamento ou por sua escritura diante de poderes constituídos, talvez seja a forma mais elevada de responsabilidade (DERRIDA, 2014, p. 53).

É possível então pensar que determinados casos exigem uma responsabilidade irresponsável e que o carnaval tal como pensado por Bakhtin pode ser um deles. O próprio ambiente cultural soviético das décadas de 1920 e 1930 em que Bakhtin desenvolve seu pensamento pode ser outro desses casos, mas agora não como uma teoria capaz de corroer o poder soviético ao evidenciar seu monologismo dialógico, mas sim como uma capaz de corroê-lo ao evidenciar as estruturas da relação promíscua entre discurso, verdade e poder.

Tal contextualização segundo os casos de seu uso é o que Safatle não faz, já que está pensando a retomada do cinismo ${ }^{11}$ no capitalismo pós-moderno através de Bakhtin passando ao largo do contexto sociopolítico da escrita de Bakhtin ${ }^{12}$. Sem esse esforço de entender sincronicamente Bakhtin, pode acontecer que sua força diacrônica seja mal compreendida. Diferentemente de meramente dar prazer ao governante que tende à tirania ${ }^{13}$ que não instauraria uma quebra entre tempo da arte e tempo da vida, nem muito menos um nexo de responsabilidade entre eles, trata-se aqui de entrever através da contextualização da carnavalização de Bakhtin - tanto internamente ao pensamento bakhtiniano em relação ao seu percurso teórico (a evolução de sua produção), quanto externamente em relação ao contexto da cultura soviética dos anos de 1920 e $1930^{14}$ - a possibilidade de haver uma responsabilidade complexa no riso cínico. Trata-se de uma responsabilidade que valoriza a separação dos âmbitos da vida e da arte como um modo de rejeitar uma redução de uma pela outra, funcionando essa valorização desse dualismo paradoxalmente como um modo de se resguardar contra o pensamento dual de uma luta entre "um contra outro" e a favor do próprio espaço da luta entre vários.

Sem analisar o estudo de Bakhtin sobre Dostoiévski, a única vez que Safatle usa o termo sátira em seu artigo não é a partir de Bakhtin, mas de Adorno, e é justamente a ideia de sátira menipeia que pode nos ajudar a pensar essa responsabilidade radical e complexa de Bakhtin que estamos investigando. Para Safatle, que retoma a análise de Adorno da sátira em Juvenal na Mínima Moralia, a sátira ocorre apenas como crítica da decadência dos costumes e, portanto, servindo à "lógica da conservação":

No parágrafo de Adorno, a ironia, em especial aquela que aparece sob a forma da sátira, é compreendida como reação do poder 
aos imperativos de mudança, isto devido ao alvo privilegiado da sátira ser normalmente a 'decadência dos costumes.' A crítica que se serve da ironia seria vinculada à lógica da conservação porque seu critério de orientação: "é sempre o critério ameaçado pelo progresso"; este permanece pressuposto como ideologia imperante, a tal ponto que o fenômeno que foge à regra é rejeitado, sem que Ihe faça a justiça de uma discussão racional. Ela se orienta assim através de um "acordo transcendental imanente", de um common sense nunca colocado em causa (SAFATLE, 2008, pp. 3-4).

Safatle não analisa então as características da sátira menipeia expostas por Bakhtin, e que poderiam levá-lo a perceber a radicalidade da posição do autor russo em relação à responsabilidade. Além disso, opera uma dicotomia entre seriedade e comicidade que o impede de ver qualquer potencial emancipador no cômico ${ }^{15}$. Entre as muitas características desse gênero, Bakhtin reivindica à sátira menipeia a capacidade de experimentar as últimas posições filosóficas, colocando em dúvida tanto os pressupostos de seu próprio discurso como do discurso filosófico-ideológico. Ao fazer isso, tal sátira não visa conservar o common sense, mas estar numa posição difícil, a de desvelar ao mesmo tempo os dois tipos de discurso: o do common sense e o do discurso dito profundo, mostrando como mesmo o segundo teria algo ainda que conservar frente ao satírico. Ela é capaz de levar a cabo esse duplo desvelamento porque sua forma explicita as estruturas discursivas e narrativas do discurso através, por exemplo, de recurso ao fantástico:

A ousadia da invenção e do fantástico combina-se na menipeia com um excepcional universalismo filosófico e uma extrema capacidade de ver o mundo. A menipeia é o gênero das "últimas questões", onde se experimentam as últimas posições filosóficas (BAKHTIN, 2013, p. 131)

Em O Mestre e Margarida, romance de M. Bulgákov escrito entre 1927 e 1940 na URSS, é justamente o elemento fantástico — a aparição de Woland, o diabo fáustico, na Moscou soviética - que expõe os alicerces da estrutura do discurso ideológico oficial em alguns de seus pontos mais sensíveis, como a construção do homem soviético, o cientificismo, o didatismo, a imprensa, o problema da moradia, etc. A presença do poder diabólico, simultaneamente extra-humano e fantástico, ao mesmo tempo se contrapõe ao poder humano oficial, revelando sua fraqueza frente à potência demoníaca, e a imita parodicamente, expondo os mecanismos de consolidação das redes discursivas que sustentam o poder
[15] É interessante observar que mesmo operando uma dicotomia aqui, o próprio Safatle é crítico das dicotomias simplificadoras em outros textos.

[16] "O dildo é a verdade da heterossexualidade como paródia" escreve Beatriz Preciado. Não acredito que seria exagerar muito sugerir a possibilidade de traduzir dildo por Woland, heterossexualidade por "poder soviético", sexo por "sistema de poder", pênis por "stalinismo" na passagem a seguir: "O dildo é a verdade da heterossexualidade como paródia. A lógica do dildo prova que os próprios termos do sistema heterossexual masculino/feminino, ativo/passivo não passam de elementos entre muitos outros de um sistema arbitrário de significação. $O$ dildo é a verdade do sexo enquanto mecanismo significante, ante a qual o pênis aparece como a falsa impostura de uma ideologia de dominação. O dildo diz: o pênis é um sexo de mentira, $O$ dildo mostra que o significante que gera a diferença sexual está capturado em seu próprio jogo. A lógica que o instituiu é a mesma lógica que o vai trair. E tudo isso sob o pretexto de uma imitação, da compreensão de uma incapacidade, de um mero suplemento prostético" (PRECIADO, 2015 pp. 84-5). 
[17] Segundo Andrade, a prosa de Bulgákov desenvolve a tal ponto a noção de paródia que: "não há mais a parodização de uma única obra, de um único autor. O recurso é ampliado para outros autores e obras, bem como para situações da realidade histórica da época, fundadas no choque entre os veIhos e os novos costumes e ideias, que são utilizados como elementos composicionais de um texto satírico original, não paródia de outro texto. O princípio de que se pode parodiar tudo" (ANDRADE, 2010, p. 274).

[18] A ideia da paródia como canto junto, ao lado de, foi desenvolvida por Andrade (2010) no âmbito dos estudos bulgakovianos e também por Campos (2005) no âmbito dos estudos fáusticos como muito próxima da sátira menipeia. Vale assinalar que os formalistas russos têm papel importante numa ressignificação da paródia, e tanto Bakhtin quanto Bulgákov compartilharam o contexto cultural em que essa operação estava sendo realizada. Ver, por exemplo, o clássico texto de Tiniánov (1968) sobre a paródia.

[19] A versão valeriana do Fausto parece se aproximar dessa inversão, já que Mefisto se torna uma espécie de caricatura de si mesmo. soviético. Nesse sentido, Woland é a verdade do poder soviético como paródia ${ }^{16}$.

Mas há outro nível paródico da prosa de Bulgákov que não é o de meramente inverter o (único) texto base parodiado. Em primeiro lugar, nesse outro nível a paródia tem como base uma multiplicidade de escrituras ${ }^{17}$. Em segundo, ela se amplia, cantando junto delas ${ }^{18}$. Woland é paródia (entre outros) do Mefistófeles goetheano; contudo, a lógica da relação entre um e outro não é a de uma dualidade presente na palavra "inversão"19 , mas a de multiplicidades complexas que se conectam e se desconectam, que se aproximam e se afastam. Nesse jogo complexo de relações múltiplas — em que outros textos bases também se relacionam em sua composição - , ocorre uma abertura para as últimas questões filosóficas, ou seja, uma ruptura ou "desmecanização" do tempo cotidiano. É neste potencial "desmecanizador", desconstrutivo, que pode haver uma força diacrônica do cômico, do satírico, do carnavalesco: uma força da atitude irresponsável como o não sério que aponta para uma responsabilidade do acontecimento.

Uma das principais coisas que Woland faz é restaurar fantasticamente o manuscrito de um romance dentro do romance - do romance do personagem Mestre que dá título à obra de Bulgákov — na realidade soviética que havia sido destruído por não ter sido autorizada sua publicação pelo aparato burocrático-administrativo stalinista. Ao ditatorialmente repor na realidade soviética o discurso de um outro, acaba por "desmecanizar" e evidenciar as relações do discurso com verdade e poder até mesmo para além da própria realidade soviética.

— Deixe-me ver [o manuscrito do romance do Mestre] — Woland estendeu a mão com a palma para cima.

— Infelizmente não posso fazê-lo — disse o Mestre — pois queimei o manuscrito no fogão.

- Desculpe-me, não acredito - respondeu Woland - isto é impossível. Os manuscritos não se queimam. - Ele se virou a Bieguemot e disse: - Bieguemot, dê-me o romance.

O gato saltou imediatamente da cadeira e todos viram que ele estava sentado sobre um maço volumoso de manuscritos. Ele pegou o exemplar que estava em cima e entregou-o, com uma reverência, a Woland (BULGÁKOV, 1992, p. 314).

O fiofó do gato-demônio desmecaniza a leitura por exigir a reflexão sobre a determinação material da escritura ao parodiar a imprensa: o manuscrito é uma mídia que foi escrita e produzida por alguém, pressupondo para isso todo um sistema de técnicas e aparatos que tem que estar funcionando, e que está em uma disputa ideológica com outros capazes de fazer o mesmo. Com isso, a sátira põe em jogo o problema ético da relação entre discurso e poder do ponto de vista mais cru e material: as condições de possibilidade de organização e es- 
truturação do aparato de inscrição para a publicação e circulação de um texto. A colocação desse problema de modo algum dá prazer ao governante - como pensa Safatle -, mas sim o põe a nu. Ao mesmo tempo, contudo, por conta das duas noções de paródia operando no romance, esse por o tirano a nu também é tirânico em $O$ Mestre e Margarida.

O único estudo de fôlego sobre a prosa de Bulgákov no Brasil dá destaque para a sua capacidade de mesclar gêneros e criar novos deles, como a ficção científica satírica (ANDRADE, 2010, p. 251-2), e aqui poderíamos acrescentar que o desenvolvimento da técnica da paródia chega a tal ponto em $O$ Mestre $e$ Margarida que o leva a criar um gênero híbrido entre o cômico e o melancólico. O aspecto cômico-melancólico do romance parece ser o seguinte: o nexo entre arte e vida, a responsabilidade, só é capaz de surgir por meio de um ato que é ao mesmo tempo fantástico e oriundo de um poder onipotente que suplanta o poder soviético oficial; ou, dito de outro modo, por meio da inescapável violência, mas não como destino de uma aparente escolha entre arte e vida (como em Bolaño), e sim como a possibilidade de abertura para essa mesma violência de que trata o autor chileno. I 


\section{REFERÊNCIAS BIBLIOGRÁFICAS}

ANDRADE, Homero Freitas de. O diabo solto em Moscou. São Paulo: EDUSP, 2002.

Apontamentos sobre a prosa satírica de Mikhail Bulgákov. São

Paulo: EDUSP, 2010.

BAKHTIN, Mikhail. Estética da Criação Verbal. São Paulo: Editora WMF Martins Fontes, 2015.

Problemas da Poética de Dostoiévski. Rio de Janeiro: Forense Universitária, 2013.

"O Problema do conteúdo, do Material e da Forma na Criação

Literária". In: Questões de Literatura e de Estética (a Teoria do Romance). São Paulo: HUCITEC EDITORA, 2010.

BOLAÑO, Roberto. Amuleto .Barcelona: Editorial Anagrama, 1999. "Ojo Silva (Putas Asesinas)". In: Cuentos: Llamadas telefónicas, Putas asesinas e El gaucho insufrible. - Barcelona : Editorial Anagrama, 2014.

BRANDIST, C. (org.); TIHANOV, G. (org.) Materializing Bakhtin: The Bakhtin Circle and Social Theory. Houndmills, Basingstoke, Hampshire; New York: Palgrave in association with St. Antony's College., 2000.

BULGÁKOV, Mikhail. O Mestre e Margarida. São Paulo: Ars Poética, 1992.

CAMPOS, Haroldo de. Deus e o diabo no Fausto de Goethe: marginália fáustica (leitura do poema, acompanhada da transcrição em português das duas cenas finais da segunda parte). São Paulo: Perspectiva, 2005.

CASTRO, Ruy. na sequência do meu texto "Esquerda/Direita: em busca dos fundamentos e reflexões críticas", e do seu postcriptum (Como uma resposta a Vladimir Safatle). In: Revista Fevereiro: http://www.revistafevereiro.com/pag. php?r=06\&t=07. 2013. Vol. 6. Acesso em: 28/10/2017.

CLARK, K., HOLQUIST, M. Mikhail Bakhtin. Cambridge e Londres: Harvard University Press, 2014. 
CLARK, T. J. "God Is Not Cast Down". In: Farewell to an Idea: Episodes from a History of Modernism. New Haven: Yale University Press, 1999.

DERRIDA, Jacques. Essa estranha instituição chamada Literatura: uma entrevista com Jacques Derrida. Belo Horizonte: Editora UFMG, 2014.

FAVARETTO, Celso. "Deslocamentos: entre a arte e a vida". In: ARS. 2011, 18, Vol. 9, p. 95 a 108.

GROYS, Boris. "Friedrich Nietzsche, Michail Bachtin, Michail Bulgakow". In: Einführung in die Anti-Philosophie. Munique: Carl Hanser Verlag, 2009.

HEIDEGGER, Martin. "Der Ursprung des Kunstwerkes (1935/36)". In: Holzwege. Frankfurt am Main: Vittorio Klostermann, 2003.

HOLQUIST, Michael Dialogism. New York: Routledge, 2010.

HOLQUIST, M. e LIAPUNOV, V. Art and Answerability: Early Philosophical Essays by M. M. Bakhtin. Austin: University of Texas Press, 1990.

NIELSEN,Greg. M. The Norms of Answerability: Social Theory Between Bakhtin and Habermas. New York: State University of New York, 2002.

PHILIPSON, Gabriel. "O cômico do Fausto de Goethe em O Mestre e Margarida de Bulgákov". In: Ipseitas, 2015. - 2 : Vol. 1. - p. 117 a 131.

PRECIADO, Beatriz. (Paul). "A lógica do dildo ou as tesouras de Derrida" In: Manifesto Contrassexual. São Paulo: N-1 edições, 2015.

SAFATLE, Vladimir. "Sobre o riso que não reconcilia: Notas a respeito da "Ideologia da ironização". In: A Parte Rei, 2008, 55.

SAMPAIO, M. C. H., ARAÚJO, K. D. de S. e MACEDO, E. B. I. de. Bakhtin e "Heidegger: caminhos para a compreensão e interpretação do acontecimento do ser na linguagem". In: Bakhtiniana, set./dez. de 2015, 3, Vol. 10., pp. 205-221. TODOROV, Tzvetan. "Prefácio à edição francesa". In: BAKHTIN, 2015.

TYNJANOV. Avanguardia e tradizione. Bari: Dedalo libri, 1968. 
VOLOSHINOV, Valentin. "Discourse in Life and Discourse" in Art. In: Freudianism. New York: Academic Press, 1976. 